\title{
Risk adjustment in health insurance and its long-term effectiveness
}

\author{
Beck, K ; Trottmann, Maria ; Zweifel, Peter
}

DOI: https://doi.org/10.1016/j.jhealeco.2010.03.009

Posted at the Zurich Open Repository and Archive, University of Zurich ZORA URL: https://doi.org/10.5167/uzh-41838

Journal Article

Accepted Version

Originally published at:

Beck, K; Trottmann, Maria; Zweifel, Peter (2010). Risk adjustment in health insurance and its long-term effectiveness. Journal of Health Economics, 29(4):489-498.

DOI: https://doi.org/10.1016/j.jhealeco.2010.03.009 


\title{
Risk Adjustment in Health Insurance and its Long-term Effectiveness ${ }^{1}$
}

\author{
Konstantin Beck ${ }^{\text {a, b, } 2 ~}$ \\ Maria Trottmann ${ }^{\mathrm{a}}$ \\ Peter Zweifel $^{\text {a }}$
}

a) Socioeconomic Institute, University of Zurich, Hottingerstrasse 10, CH-8032 Zurich, Switzerland

b) CSS Institute for Empirical Health Economics, Tribschenstrasse 21, CH-6002 Lucerne, Switzerland

\section{Revised Version, February 2010}

e-mail adresses:

Konstantin Beck: $\quad$ konstantin.beck@css.ch

Maria Trottmann: maria.trottmann@soi.uzh.ch

Peter Zweifel: $\quad$ pzweifel@soi.unizh.ch

\footnotetext{
${ }^{1}$ An earlier version of this paper was presented at the $7^{\text {th }}$ conference of the European Risk Adjustment Network (RAN), March 2006 in Berlin, Germany. The authors thank the members of the RAN, especially Wynand van de Ven and Erik Schokkaert, and two anonymous referees for their helpful comments.

${ }^{2}$ Corresponding author: Konstantin Beck/ CSS Institute for Empirical Health Economics/ Tribschenstrasse 21/ CH6002 Lucerne/ Switzerland / telephone: ++41 5827711 11/fax: ++41 5827715 16/ e-mail: konstantin.beck@css.ch/ website: www.css-institute.ch
} 


\section{Introduction}

Enthoven's proposal for regulated competition between social health insurers (Enthoven 1978) has been used as a blueprint for reform in several countries (see van de Ven et al. 2006). One example is Switzerland with its comprehensive mandatory coverage for all citizens, offered by some 80 competing nonprofit health insurers. The new law of 1994 calls for semiannual open enrollment and community-rated premiums within the same fund. Premium reductions for adults within a given fund are only possible for contractual differences such as a higher deductible. However, with every adult paying the same premium - within a given fund for the same type of contract - but expected health care expenditure (HCE) varying widely, strong incentives for risk selection are created in the absence of an adequate risk adjustment scheme. Although risk selection is illegal, its prevalence in Swiss social health insurance has been reported repeatedly (Beck and Zweifel 1998, Beck et al. 2003). As van de Ven and Ellis (2000, section 2.5) argue, risk selection produces no benefits to society (unless a dynamic view is adopted, where the threat of being classified as an unfavorable risk in the future helps to reduce moral hazard).

The objective of risk adjustment is to mitigate incentives for risk selection. To this end, insurers with a below-average share of female and elderly consumers have to contribute to the risk adjustment fund, while insurers with an above-average share receive a payment from the fund. So far, the different schemes have been judged mainly in terms of their ability to predict individual HCE one year ahead (Newhouse et al. 1989, van Barneveld et al. 2000, Holly et al. 2003).

This criterion is subject to at least two criticisms. First, risk selection is not costless to insurers. As pointed out by van Barneveld et al. (2000) as well as Zweifel and Breuer (2006), this means that they will invest in this activity only if expected profits exceed the cost. However, the regression criterion of minimizing squared prediction error with regard to $\mathrm{HCE}$ fails to take cost considerations into account. In our model, we address the problem of costly risk selection activities by restricting attention to selection profits and losses exceeding a given annual threshold. Second, Zweifel and Breuer argue that insurers who want to stay in business must have an eye on present values rather than one-period profits.

This paper, then, follows the lead of Shen and Ellis (2002) by estimating expected profits attainable from risk selection, given the information available to the insurer. It therefore only models the classification of risk types, neglecting the problem of how to attract or deter types. However, if profits are large enough, strategies to perform risk selection will most certainly be developed by crafty insurers.

However, unlike Shen and Ellis (2002), the present analysis assesses the impact of risk adjustment if insurers' planning horizon exceeds one year. In an attempt to reflect longer planning horizons 
(which agree with insurers' preference for long-run contracts and guaranteed renewability unless prevented by regulation (Pauly et al. 1998)), the period of observation for expected profits is extended to five years in the body of the paper. This permits to take into account the fact that a currently favorable risk may develop into an unfavorable one, switch to a competitor, or die. Conversely, an unfavorable risk may recover to become a favorable one in the future. In the theory of statistics, these effects are known as "regression towards the mean" (Welch 1985; Beck 2004). The empirical relevance of the regression towards the mean effect is assessed by varying the planning horizon from one to five years. This is possible thanks to a panel data set covering some 180,000 individuals over eight years.

The reminder of this article is structured as follows. In section 2, a model of the insurer's decision to select risks is formulated, which subsequently permits to calculate the financial reward from this activity. After a description of the risk adjustment schemes and the database in section 3, the details of the empirical estimation are explained in section 4. Results are presented in section 5. They indicate that even a crude adjustment in the risk adjustment formula to take future HCE into account serves to neutralize incentives for risk selection to a substantial extent also over a longer planning horizon. The final section 6 is devoted to a summary and conclusions.

\section{Modeling risk selection}

\subsection{What risks to attract or deter?}

The objective of this section is to model a health insurer's decision to attract or deter certain risk types. This decision is assumed to reflect insurers' expected profits or losses $\left(E\left[\pi_{i, j}\right]\right)$ pertaining to costumer $(i)$, taking into account the risk adjustment formula $(j)$ applied by the regulator. To estimate this quantity, five elements must be considered; viz. (1) the expected fair community-rated premium $\left(E\left[P_{i, t, j}\right]\right),(2)$ expected health care expenditure $\left(E\left[H C E_{i, t}\right]\right),(3)$ the expected contribution to the risk adjustment scheme ( $\left.E\left[R A_{i, t, j}\right]\right)$, a positive quantity for favorable risks, a negative one for unfavorable ones, its value depending on the risk adjustment formula $(j)^{3}$, and (4) the probability of an individual dying $\left(p_{i, t}^{\text {death }}\right)$ or $(5)$ switching to a competitor $\left(p_{i, t}^{\text {switch }}\right)$. This all boils down to expression (1), with the interest rate $r$ (set to 0.06 throughout this paper) used to discount future payments,

(1) $E\left[\pi_{i, j}\right]=\sum_{t=2000}^{2004}\left(E\left[P_{i, t, j}\right]-E\left[H C E_{i, t}\right]+E\left[R A_{i, t, j}\right]\right) \prod_{h=2000}^{t}\left(1-p_{i, h}^{\text {death }}\right) \prod_{k=2001}^{t}\left(1-p_{i, k}^{\text {switch }}\right) \frac{1}{(1+r)^{t-2000}}$.

\footnotetext{
${ }^{3}$ All formulas are constructed in a way to guarantee that the sum of contributions to risk adjustment paid by low risks is exactly balanced out by the sum of subsidies paid out for high risks.
} 
Loadings for administrative expenses are neglected, because they are part of $E\left[P_{i, t, j}\right]$ and $E\left[H C E_{i, t}\right]$ but do not enter $E\left[R A_{i, t, j}\right]$. Note that HCE does not depend on the type of risk adjustment imposed, although insurers' incentives to combat moral hazard (by launching product innovations) may well be weakened by risk adjustment (Zweifel 2007). The assumed planning horizon comprises the years 2000 (defined as "current") to 2004. Insurers' actual planning horizons might be even longer; however, data availability dictates one of no more than five years. This should be sufficient to at least approximate expected long-term profits. Following the approach proposed by van Barneveld et al. (2000), only „sufficiently large“ profits or losses are assumed to cause risk selection activities. Profits in principle are „sufficiently large“ if returns to risk selection exceed its total cost, which not only comprises the expenses for product development, marketing, and actual administration of the risk portfolio but also the loss of reputation if found out by the media or the regulator. Clearly, information to estimate this quantity is not publicly accessible. Therefore, it is simply assumed that expected profits from risk selection must exceed CHF 1,000 (=\$800 at 2006 exchange rates) per annum and individual in present value to trigger selection activities. In a sensitivity analysis, results changed surprisingly little when the threshold was lowered to CHF 400 and increased to CHF 1,200 p.a. The impact of this ad hoc assumption is therefore limited.

According to Table 1, all customers are divided into four mutually exclusive subsets. Group A contains all individuals with expected profits in excess of CHF 1000 p.a., while B has those with expected profits up to CHF 1,000 p.a. Conversely, C contains all individuals with expected losses up to CHF 1,000 p.a. and D those with losses beyond CHF 1,000 p.a.

\section{TABLE 1 ABOUT HERE}

Therefore, $\mathrm{A}$ is the set of risks the insurer seeks to attract, D contains the risks it wants to deter, while $\mathrm{B}$ and $\mathrm{C}$ are the risks that do not call for any risk selection effort. It is important to note that risk selection does not describe a "young-and-healthy-people-only" strategy under all circumstances. As shown in section 5.2, risk adjustment can turn elderly and even chronically ill individuals into favorable risks.

\subsection{Profits due to risk selection}

In order to assess the effectiveness of risk adjustment, the insurer's profits are calculated under the assumption that it had successfully applied the selection strategy described by table 1 . The ex-post or realized profits generated by individual $i$ and associated with risk adjustment scheme $j$ are specified as follows, 


$$
\pi_{i, j}=\sum_{t=2000}^{2004}\left(P_{i, t, j}-H C E_{i, t}+R A_{i, t, j}\right) \frac{1}{(1+r)^{t-2000}} \frac{1}{\tau_{t}} \quad \text { with } \tau_{t}=\frac{\sum_{i} H C E_{i, t} / \sum_{i} m_{i, t}}{\sum_{i} H C E_{i, 2000} / \sum_{i} m_{i, 2000}}
$$

Here $\tau_{\mathrm{t}}$ is a deflator and $m_{\mathrm{i}, \mathrm{t}}$ is the number of months individual $i$ is enrolled during a given year. Since $\tau_{\mathrm{t}}$ reflects the general development of HCE since 2000, real profits are defined in terms of the cost of health care. Transformation to real terms facilitates the comparison of ex-post profits with ex-ante expectations. The latter (see equation (1)) are calculated in real terms for simplicity since risk classification is not affected by general inflation. Considering first the strategy of deterring unfavorable risks, the financial benefit attainable, $\Pi$, is defined as profits contributed by the remaining risk types (i.e. A, B, and C) relative to their total (deflated) premium revenue,

$$
\Pi_{[\operatorname{deter} \mathrm{D}]}=\frac{\sum_{i \in\{A, B, C\}} \pi_{i, j}}{\sum_{i \in\{A, B, C\}} \sum_{t=2000}^{2004} P_{i, t, j} \frac{1}{\tau_{t}} \frac{1}{(1+r)^{t-2000}}}
$$

Note that while labels A, B, C denote those individuals the insurer expects to be preferred or neutral risks (according to Table 1), formula (3) calculates realized profits from A, B and C- type customers. The same is true for formula (4) below. Realized figures serve to simulate the future profits associated with the choice of a risk-deterring strategy in the year 2000.

The other strategy, attracting good risks, has to be defined differently because it is inconceivable that the population insured consist of subset A only. Rather, let $x>1$ be the factor by which the size of $\mathrm{A}$ is increased (for example by strategically promoting high-deductible plans known in social health insurance in the Netherlands or Switzerland to provoke self-selection by low risks). Then, realized financial benefit is given by

$$
\Pi_{[\mathrm{attractA}]}=\frac{(x-1) \sum_{i \in A} \pi_{i, j}}{(x-1) \sum_{i \in A} \sum_{t=2000}^{2004} P_{i, t, j} \frac{1}{\tau_{t}} \frac{1}{(1+r)^{t-2000}}+\sum_{i} \sum_{t=2000}^{2004} P_{i, t, j} \frac{1}{\tau_{t}} \frac{1}{(1+r)^{t-2000}}} .
$$

If, for example, an insurer is able to triple its share of preferred A-type customers, its realized profits will increase by $2 \sum_{i \in A} \pi_{i, j}$ relative to a premium volume that itself increases by the first term in the denominator, i.e. $2 \sum_{i \in A} \sum_{t=2000}^{2004} P_{i, t, j} \frac{1}{\tau_{t}} \frac{1}{(1+r)^{t-2000}}$. 
The more effective the risk adjustment, the smaller are these profits. As Beck and Zweifel (1998) point out, however, risk selection is a risky business. Some customers who are expected to be profitable will in effect turn out to be unfavorable risks, while some who are deemed unfavorable will in fact contribute to profits. As will be seen in section 5.3, this uncertainty increases when the risk adjustment formula is refined.

\section{Policy setting and data}

\subsection{Risk adjustment schemes considered}

The profits of risk selection are assessed in four different scenarios. The $R A_{i, t, j}$ values appearing in equations (1) and (2) are calculated according to the four risk adjustment schemes. They are retrospective rather than prospective, as in current Swiss regulation.

(0) No risk adjustment

The first scenario is a benchmark with no risk adjustment scheme in place.

(1) Demographic risk adjustment

Current Swiss risk adjustment uses 28 age and gender groups (26-30, 31-35 ...91+), as in table 4. While these age groups are purely arbitrary, they are established in the market. The possibility of optimizing them for risk adjustment will therefore not be considered here. Also, payments are calculated regionally. To avoid small sample problems in the top age groups of small cantons, this detail is neglected by treating Switzerland as one region.

(2) Demographic risk adjustment augmented by prior hospitalization

This formula is part of a reform passed by Swiss parliament in 2007. Retaining current age and gender groups, it includes a dummy variable indicating hospitalization during the previous year. Empirical evidence presented by Beck (1998) and Holly et al. (2003) shows HCE to be substantially higher for individuals with hospital stays ${ }^{4}$ during the previous year. However, insurers might have an incentive to encourage short-term hospitalizations with the mere aim of receiving payments from the risk adjustment scheme. Therefore, only inpatient stays of three or more days are considered to be a hospitalization. Note that it is not the cost of the inpatient stay itself that is taken into account but the increased predicted HCE during the year following the stay. Therefore any manipulation of this adjuster would pay off only if this extra HCE were to exceed the cost of the hospitalization itself, which is very unlikely in the case of long stays.

\footnotetext{
${ }^{4}$ Inpatient stays related to maternity are excluded.
} 
(3) Demographic risk adjustment augmented by prior hospitalization and PCGs

The final alternative to be considered is to augment existing demographic risk adjustment by both the indicator for prior hospitalization and Pharmaceutical Cost Groups (PCGs). There are 13 PCGs which are similar to those developed by Lamers and Van Vliet (2003). They were adapted to Swiss data by a team at CSS (Beck et al. 2006, ch. 4.2).

As with all patient classification systems, the issue of how to deal with patients belonging to more than one class has to be addressed. Here, the sorting algorithm used by Pope et al. (2000) is employed by first calculating mean HCE by PCG for the entire sample and assigning the PCG with the highest value rank one and excluding its members from further calculations. Next, mean HCE is recalculated for the reduced sample, assigning the PCG with the highest value rank two, and so on. Finally, patients with more than one condition are assigned to the PCG with the highest rank.

\section{TABLE 2 ABOUT HERE}

The predictive power of the four risk adjustment formulas is shown in Table 3 . The $\mathrm{R}^{2}$ values are high, mainly for two reasons. First, Swiss health insurers only pay roughly one-half of inpatient HCE, in keeping with the Law of Health Insurance of 1994. One-half of the bill is funded by cantonal governments, who heavily subsidize public hospitals. Since very high HCE are almost always due to hospitalization, outliers do not fully show in the data, causing goodness of fit to increase. Second, the marked increase in $\mathrm{R}^{2}$ from variant (2) to variant (3) can be explained by the fact that little prediction is involved because the observations on PCGs pertain to the same year as those on HCE. Table 3 also shows that even with PCG information included, the regulator (who has to disregard prior HCE for maintaining health insurers' incentive to control cost) cannot catch up with the health insurers, who dispose of a good deal of additional information which can be used to increase $\mathrm{R}^{2}$ to 0.48 (see section 4.2 for details).

\section{TABLE 3 ABOUT HERE}

\subsection{The data}

The sample contains individual data from 182,529 adults (aged 26+) enrolled by CSS, the leading sickness fund of Switzerland, during the full year of 1999 and not enrolled in a Managed Care plan during the period of observation. For data quality reasons, only residents of the French and Italian 
speaking parts of Switzerland are included. ${ }^{5}$ Individuals were observed from 1997 to 2004, with 1997 to 1999 used for prediction. The insurer is assumed to undertake its risk selection effort once and for all at the beginning of the year 2000. The data from 2000 to 2004 serve for calculating the present value of profits it would have made by pursuing the respective strategy.

\section{Calculating the components of profits and losses}

To calculate expected profits from risk selection according to expression (1), all components such as expected premiums, expected HCE, expected payments into and from the risk adjustment fund as well as probabilities of death and of switching to a competitor need to be determined. This section is devoted to these issues.

\subsection{Expected premiums}

In a competitive market with entry and exit, total premium revenue equals total expected cost, the latter made up of expected HCE plus a loading. Since the admissible loading (of about five percent) is part of premium revenue as well as of cost, it does not affect individual contributions to profit and is therefore neglected ${ }^{6}$. Premiums must be community-rated for all adults within the same fund, region, and coverage option (e.g. deductible level). Premium reductions for high-deductible plans are possible, but - due to regulation - fall short of their risk-rated amounts. Contracts with high deductibles are especially attractive to low risks, causing them to be an effective means for risk selection. Perfect risk adjustment would neutralize these incentives; however, given imperfect adjustment formulas - and all formulas analyzed in this study are imperfect - differences in expected profits across deductible options remain. As a consequence, high-deductible plans cross-subsidize low-deductible plans. Therefore consumers choosing high-deductible plans become preferred risks to insurers.

In order to be able to use observed values, the insurer considered is assumed to have predicted total HCE of the benchmark year 2000 with perfect precision. Moreover, to simplify calculations, inflation during the forecasting period $2001-2004$ is neglected. In fact, as long as inflation affects all components of eq. (1) in the same way (including payments to / from the risk adjustment scheme),

\footnotetext{
${ }^{5}$ Due to different billing modalities, detailed information on drug expenditure is of good quality only in the French and Italian speaking parts of the country. Except for the Pharmaceutical Cost Group variant of risk adjustment, the analysis presented in sections 4 and 5 was repeated using a larger sample containing 250,000 insured from all parts of the country. Results were very similar to those presented here.

6 A detailed analysis of administrative expenses might show different loadings for different risk groups; however, this goes beyond the scope of this study.
} 
real profits do not change. Therefore, calculated premiums $E\left[P_{i, t, j}\right]$ are constant over these four years.

\subsection{Expected health care expenditure}

Predicted individual HCE is derived from prior experience, covering the years $1997-1999$. The year 1999 was complete, while missing entries from 1997 or 1998 were replaced by the average values pertaining to their demographic group. Insurers know past individual HCE for existing enrollees. For new enrollees, they can predict HCE using information from questionnaires that have to be filled by new applicants for supplementary insurance (which is regulated differently, by the Law on Insurance Contracts). Only switchers having no more than compulsory coverage are not made to declare their health status. Still, sales personnel obtains an (often visual) impression of the customer's health. The choice of deductible for the compulsory part also helps to predict HCE.

Future individual HCE is estimated in three steps. The first is an OLS regression with HCE in 2000 net of deductible and coinsurance as the dependent variable. Despite the fact that about 30 percent of individuals did not consume health care in excess of their deductible and the high skewness of positive HCE, untransformed OLS estimation is the preferred method of estimation. In a comparison of alternative models (e.g. a two-part logarithmic model with 'smearing estimate' retransformation (Duan et al. 1984) and a GLM model with a log link and a gamma family (Manning and Mullahy 2001)), untransformed OLS was found to have the smallest mean squared and smallest mean absolute prediction error. It performed particularly well at predicting very high HCE, which is of crucial importance to the insurer. Similar findings have been reported by e.g. Pauly and Herring (1999, p. 41), Holly et al. (2003), and Ellis (2008). The explanatory variables are age classes interacted with gender, deductibles as of year 2000, HCE in 1997, 1998, and 1999 (the latter split up in its components, viz. physician's services, drugs dispensed by physicians, drugs dispensed by pharmacies, inpatient care, home care, nursing home care, and other expenditure).

The regression results appear in Table 4, with its first three columns showing age and gender effects, while its last two columns contain the estimates pertaining to the remaining regressors. Since the normality assumption does not hold in view of skewness, distribution-free Tchebycheff significance levels are also reported.

\section{TABLE 4 ABOUT HERE}

Except for the constant which is negative, all coefficients have the expected signs. For women, HCE attains a maximum (ceteris paribus) in the 26 - 30 age group (due to maternity), but rises consistently between age groups $41-45$ and $86-90$. Beyond age 90 (men 85) age coefficients go 
down. Otherwise, men display a consistent increase of HCE with age. In a second step, individual HCE in 2004 is predicted using the 1997 - 1999 values of explanatory variables (age as of 2004). Negative predicted values (occurring among about 5 percent of insured) are replaced by zeroes. The third step consists in interpolating between the predicted 2004 and the observed 1999 values, in accordance with eq. (5). This procedure can be justified by noting that observed HCE contains transitory components, while the predicted 2004 values are purged of them. By smoothing HCE values prior to 2004 as well, interpolation serves the accuracy of prediction. For the choice of the interpolation formula, a natural assumption is that insurers increasingly discount the transitory component as time goes by. Using exponential decay, the formula reads

$$
E\left[H C E_{i, t}\right]=E\left[H C E_{i, 2004}\right]-(0.5)^{t-1999}\left(E\left[H C E_{i, 2004}\right]-H C E_{i, 1999}\right) ; \text { for } t \in\{2000,2001, \ldots, 2003\}
$$

It amounts to van Vliet's (1992) moving average variant (MA) of his implementation of the "regression to the mean hypothesis" by Welch (1985). All three variants (a simple autoregressive (AR) model, an AR variance component model, and an ARMA model) were fitted to the residuals of a HCE regression using individual data of 33,987 Swiss insured from 1990 to 1997. The three specifications yielded very similar AR coefficients, ranging between 0.491 and 0.521 (Beck, 2004, ch. 5). These findings support the use of formula (5).

\subsection{Expected payments from / to the risk adjustment fund}

The ex-post calculation of the different risk adjustment formulas is straightforward. By way of contrast, modeling the insurer's expectations $\left(E\left[R A_{i, t, j}\right]\right.$ in expression (1)) raises a few issues. When applying the different risk adjustment schemes to future years (2001-2004), age is known while gender and existing chronic illness can be assumed to remain constant. Individuals who will develop chronic conditions are aggregated with the low risks, assuming that they cannot be identified. By way of contrast, knowing that about 12 percent of enrollees had at least one hospital stay during the preceding year, the insurer associates by assumption the top 12 percent in terms of total HCE with those that will have a hospital stay (relevant for risk adjustment schemes no. (2) and (3)).

\subsection{Probability of leaving the insurer}

As evidenced by eq. (1), two probabilities need to be distinguished here, the probability of death, $\left(p_{i, h}^{\text {death }}\right)$ and the probability of switching to another insurer, $\left(p_{i, k}^{\text {switch }}\right)$. Estimating $\left(p_{i, h}^{\text {death }}\right)$ specifically for this population turned out to be impossible because of the small number of deceased in the sam- 
ple. Instead, life tables provided by the Federal Statistical Office were used, which are grouped by age and gender. However, high HCE have been found to be strongly related to death by e. g. Zweifel et al. (2004). The probability of death is therefore certainly underrated for high-cost individuals, since they are more likely than others to drop out of the sample in the course of the forecasting period. This results in an overestimate of expected HCE.

To estimate the probability of an insured switching to a competitor $\left(p_{i, k}^{\text {switch }}\right)$, a logistic regression model is used (Beck 2004, ch. 9). This probability is calculated each year, applying the same, constant coefficients (estimated by Beck (2004) on a different set of data). The model comprises age, years of CSS membership, number of supplementary insurance products, and premium relative to the market average as explanatory variables. Age has a negative effect, accounting for the decreased mobility of older individuals. Duration of membership also has a negative effect because loyal members tend to remain loyal. Insured with several supplementary insurance products have more difficulty switching because the open enrollment requirement holds only for the compulsory component of coverage. Legally, it is possible to buy compulsory and supplementary coverage from different insurers, but consumers are afraid of insurers haggling over their obligation to pay, which easily results in delayed reimbursement. ${ }^{7}$

\section{Results}

\subsection{Risk adjustment and the distribution of expected individual profits}

The choice of the risk adjustment scheme has a strong impact on the distribution of predicted individual profits and losses. As profits are zero in a competitive market, $\frac{1}{n} \sum_{i=1}^{n} E\left[\pi_{i, j}\right]$ is zero in all scenarios. Without risk adjustment $(j=0)$, the distribution is heavily skewed to the right, and exhibiting a marked tail of very sizeable losses (Figure 1, tail cut at -20,000). With a risk adjustment scheme including prior hospitalization and PCGs $(j=3)$ the distribution of $\pi_{i, 3}$ is almost symmetrically centered at zero (Figure 2), with its median value equal to CHF 489, down from CHF 5,985 with no risk adjustment. However, there is a heavy tail of very profitable consumers, who (in expectation) seem to be overpaid by the risk adjustment scheme.

\section{FIGURES 1 AND 2 ABOUT HERE}

\footnotetext{
${ }^{7}$ Finally, a high CSS premium relative to the market average encourages consumers to switch. However, construction of this variable in the present context would have required modeling the premium development of competitors (which in turn would depend also on payments into and from the risk adjustment scheme). Therefore, this ratio is set equal to one to avoid this complication.
} 
The objective of risk adjustment is to neutralize insurers' incentive for risk selection given that premiums are regulated not to reflect true risk. It therefore should affect the composition of the risk pool in terms of the subsets A through D distinguished in section 2 above. Indeed, variant (3) causes the share of risks in subgroup A (expected individual profit > CHF 1,000 p.a.) to drop from 56 percent (no risk adjustment) to a minimum of 20 percent. Since the left tail is not thinned out completely (compare figures 1 and 2), the share of individuals in the unfavorable group D decreases only slightly from 21 to 18 percent. Table 5 exhibits the full set of estimates. However, as will be shown in the next section, risk adjustment causes the composition of these groups to change completely.

\section{TABLE 5 ABOUT HERE}

\subsection{Effect of risk adjustment on the characteristics of subgroups}

Risk adjustment may have an important effect on the characteristics of the subgroups making up the risk pool. This effect seems to have been largely neglected in the literature. However, the political acceptance of a risk adjustment scheme strongly depends on its distributional impacts. Since incomes are not known, the analysis of this section is limited to age and two indicators of health status, viz. HCE prior to risk adjustment and membership in one or more PCG.

Without risk adjustment (0), profitable members (A) are pretty much the usual suspects, viz. younger than average, low net HCE and rare PCG membership, indicating absence of chronic illness (see Table 6). Unsurprisingly, demographic risk adjustment (1) changes this picture strongly in terms of age, causing mean age in subgroup A to increase from 46 to 62 years. Conversely, average age drops by as much as 20 years in subgroups B and C while it still decreases by 11 years in subgroup D. At the same time, HCE (net of cost sharing) more than doubles in subgroup A, while membership in at least one PCG more than triples, reaching 11 percent (not far below the overall share of 15 percent). This indicates that even mere demographic risk adjustment can turn some chronically ill individuals into profitable customers. However, the D subgroup continues to have by far the highest average HCE and share of PCG members.

\section{TABLE 6 ABOUT HERE}

When prior hospitalization is included in the type (2) risk adjustment scheme, characteristics of the subgroups change again. Average age in the A group even increases to 70, exceeding the value implied by the demographic formula (1). Because morbidity is higher among the elderly, they are more likely to get a morbidity-related subsidy, making them attractive risks to the insurer. The change in the composition with regard to health status is even more striking. Average net HCE in 
the subgroup A now is CHF 328, exceeding the overall mean of CHF 291 per month. Likewise, A now contains 20 percent individuals who are in some PCG (overall mean, 15 percent). Put the other way round, many ill people may now contribute to expected profit even if their expected HCE is above average, while the very healthy are transformed into average risks because they are loaded with payments to the risk adjustment scheme.

When PCGs are also included into the scheme (type 3), average age remains roughly the same in all subgroups. However, average net HCE in the A group increases, while those of the unfavorable D group decrease once more, to CHF 631 per month (which is still more than twice the overall mean of CHF 291). The most amazing change, however, is in PCG membership. The A subgroup now consists of 47 percent chronically ill.

In sum, this analysis offers important insights into the workings of risk adjustment schemes (2) and (3). By collecting transfers from healthy people, they transform them (on average) from very favorable into medium risks from the insurer's point of view. The high risks on the other hand come with a subsidy, making some of them very profitable. These profits indicate an overpayment by the risk adjustment scheme, which can be explained as follows. While the subsidy equalizes average expected contributions across risk groups, a majority of individuals has HCE below group average because the distribution of HCE is skewed to the right even within a risk group, with a long tail towards high values.

Before turning to the financial benefits attainable by risk selection, two points should be mentioned. First, a morbidity-based risk adjustment makes it more difficult to recognize risks. With no or only demographic risk adjustment, it is sufficient for insurers to gather information about prior utilization and personal well being, whereas with schemes of type (3), they will have to establish precisely those chronic conditions that yield the highest contributions - a far more complex task. The second point concerns risk selection through quality of services covered. As pointed out by e.g. Newhouse (1982) and van de Ven and Ellis (2000), insurers may try to stave off unfavorable risks by e. g. incorporating lower quality care for the chronically ill (always on the premise of community rating combined with imperfect risk adjustment). This form of selection hurts some of the weakest. Moreover, it is difficult to contain because service quality cannot easily be regulated (Marcheand et al. 2004). The authors cited agree in their expectation that morbidity-related risk adjustment of the types (2) and (3) are a suitable tool to prevent this type of selection. The present analysis supports this notion by showing that scheme (3) causes the most favorable risk group to contain a large number of chronically ill individuals, who are eschewed by insurers who offer them benefits of lower quality. Conversely, insurers with a small market share (and therefore little influence on mean HCE) may benefit by attracting the chronically ill through special programs. In the Netherlands, 
where morbidity indicators are included in the risk adjustment scheme, an insurer in fact developed a disease management program for diabetes patients (van de Ven et al. 2006).

\subsection{Estimating the financial incentive for risk selection}

In this section, we derive an estimate of the financial gains from risk selection by calculating expost profits associated with the strategies described. According to equation (2), these profits are a function of the risk adjustment schemes (0) to (3). The financial advantage due to risk selection is expressed as the ability to offer a lower premium, which almost certainly leads to a favorable market position in view of strong price competition. From the moment an insured in our sample dies or switches to another insurer, her cash flow drops to zero, as in real life. All figures are in prices of 2000.

First, the strategy of deterring expectedly unfavorable risks (D) is evaluated. An insurer capable of getting rid of all expectedly unfavorable risks (D) could reduce its average premium level by as much as 46 percent on expectation when there is no risk adjustment at all (see Table 7). Introducing age and gender as risk adjusters already serves to reduce the potential for premium reductions by one third. The most elaborate variant (3) achieves a reduction of two thirds, to 16 percent.

\section{TABLE 7 ABOUT HERE}

The other strategy is to attract risks that are expected to be favorable (A). Let $x$ denote the factor by which the number of $\mathrm{A}$ - rated costumers is increased, the number of risks in all other subgroups held constant. If $x$ goes to infinity, the risk portfolio consists to over 99 percent of A-rated customers. Because many Swiss insurers are rather small, $4 \leq x \leq 6$ are considered realistic values. Without risk adjustment, this strategy on expectation permits a lowering of the premium level by 48 percent ( $x=6$, in table 8). Demographic adjustment (1) reduces this figure to 38 percent. However, it takes schemes (2) and (3) involving prior hospitalization and PCGs to largely reduce the financial gains associated with "chasing the good risks".

\section{TABLE 8 ABOUT HERE}

The entries of tables 7 and 8 indicate that even in the long run, "regression to the mean" does not equalize risk profiles. Without risk adjustment, both deterring unfavorable and attracting favorable risks are highly profitable strategies. However, adding the crude morbidity indicator, prior hospitalization, works surprisingly well to neutralize these gains. A possible explanation is the fact that hospitalization is a good proxy for HCE in earlier years, which are used for prediction by the insur- 
ers. ${ }^{8}$ It is well known that risk adjustment schemes work best if they predict cost to the same degree as insurers themselves.

The contribution of PCGs on the other hand is somewhat disappointing, raising doubts whether the administrative expense for establishing them is worthwhile. However, table 6 shows that the risk adjustment formula (3) including PCGs excels in directing subsidies specifically to individuals with consistently high HCE. The incentive to skimp on the quality of care for the chronically ill is certainly the weakest with this formula.

As shown in table 9, misclassification is likely to occur, its extent clearly depending on the risk adjustment scheme implemented. For example, the fraction of individuals rated A who ex post generated losses is 7 percent without risk adjustment but 25 percent with risk adjustment (3). In other words, with risk adjustment (3) in place, as many as one-fourth of all seemingly very attractive customers were misclassified. For the D-rated customers, the frequency of misclassification is quite high for all risk adjustment schemes. This likely reflects the fact that - due to the lack of diagnostic information - predictions were based on total prior cost, failing to distinguish between acute and chronic illnesses. Again, false classifications occurred more frequently with a morbidity-based risk adjustment scheme in place. These results confirm our previous claim (section 5.2) that a morbiditybased risk adjustment scheme makes it more difficult to distinguish between profitable and unprofitable risks. In the absence of risk adjustment, unprofitable risks are simply all customers with above - average HCE, for example all chronically ill individuals. By subsidizing some conditions leading to high HCE, morbidity-based risk adjustment changes this, turning some of the high risks into to very profitable customers (see table 6). In sum, morbidity-based risk adjustment requires a much more careful screening of individual risk profiles and health conditions by insurers seeking to pick profitable risk.

\section{TABLE 9 ABOUT HERE}

\subsection{Variation of the planning horizon}

As stated in the Introduction, it is reasonable to assume that insurers plan over a period of several years. In order to assess the importance of this consideration, equations (1) to (4) were recalculated assuming planning horizons of four, three, two, and one year ${ }^{9}$. The calculation of these models is straightforward. In expressions (1) to (4), the summation stops at the pertinent year prior to 2004 .

\footnotetext{
${ }^{8}$ We thank Erik Schokkaert for pointing this out.

${ }_{9}$ We thank Mathias Kifmann, our discussant at the 19th annual meeting of the Health Economics Working Party within the Verein für Socialpolitik, and an anonymous referee for pointing this out.
} 
To estimate expected HCE, formula (5) is applied replacing $E\left[H C E_{i, 2004}\right]$ by $E\left[H C E_{i, t}\right]$, with $t \in\{2000,2001, \ldots, 2003\}$.

With a shorter planning horizon, a considerably higher share of individuals were classified as very profitable A-types (see table 10). For example, with a one-year planning horizon and risk adjustment (3), 40 percent of customers would have been classified as A as opposed to 20 percent with a five-year planning horizon. This is likely due to the 'regression-to-the-mean' specification of the forecasting model. For instance, let an elderly lady have small observed HCE in 1999. Then, her forecast HCE for 2000 would be quite low as well according to equation (5). Over the years, however, predicted values approach the high (conditional) mean HCE of a person of her type. The other components of equation (1) being largely independent of the planning horizon, her rating might well drop from $\mathrm{A}$ in the one-year analysis to a $\mathrm{B}$ or $\mathrm{C}$ in the longer term.

\section{TABLE 10 ABOUT HERE}

At the other end, however, the number of D-rated customers does not vary much with the planning horizon (see table 10). In fact, those who had high HCE in 1999 are mostly predicted to have high HCE in all subsequent years. This is especially true for those with high drug or long term care expenditure, which point to chronic illness (see table 4). Indeed, the entries of table 4 suggest the existence of a basically healthy type (with a low autoregressive element in HCE) and a chronic type (with a high element). This difference has implications for the risk of misclassification as a function of the planning horizon (see table 11).

\section{TABLE 11 ABOUT HERE}

Considering A-rated customers first, their low autoregressive element in HCE causes predictability to decrease with length of planning horizon in principle [see rows (1) through (3)]. The countervailing effect is regression to the conditional mean, which may make for more accuracy of prediction if the insurer selects risk based on observable characteristics unfettered by risk adjustment [see row (0)]. Turning to D-rated individuals, their high HCE is the consequence of a whole host of causes, resulting in a low degree of predictability and hence high frequency of misclassification. However, this group comprises an important share of chronically ill with their marked element of autoregression in HCE. This may explain why the risk of misclassification, while high compared to A-rated customers, decreases with length of the time horizon. 
Finally, table 12 displays the profits associated with risk selection as function of the planning horizon. Starting with the strategy of attracting A-rated risks, the gains tend to increase, which accords with the finding that the frequency of misclassification decreases in the absence of risk adjustment [row (0) of tables 11 and 12]. By way of contrast, refinements of the risk adjustment formula cause gains not only to be lower but to decrease with the planning horizon [rows (1) to (3), again in keeping with table 11]. In the case of D-rated customers, gains have a similar pattern [row (0) of table 12], likely reflecting the tendency for predictability of HCE to improve [row (0) of table 11]. Again, these gains are reduced strongly by refinements of the risk adjustment formula.

Reading table 12 vertically column by column, one sees that the gains from attracting A-rated or deterring D-rated customers can be reduced by at least one-half by the more refined risk adjustment formulas (2) and (3). Therefore, the relative effectiveness of the risk adjustment formulas neither hinges on the insurer's choice of planning horizon nor on the length of its planning horizon. 


\section{Conclusions}

There is a broad consensus that given managed competition with community-rated premiums, risk adjustment becomes a necessary regulation of health insurance markets. However, while a purely demographic risk adjustment formula has been recognized as being insufficient, its precise specification has remained controversial. Most of the empirical literature describes and tests for the relationship between a set of morbidity indicators and HCE of one year. This short time horizon is in accordance with the fact that managed competition usually allows for annual open enrollment. However, insurers have a strong interest in long-term customers in view of considerable acquisition cost. Moreover, consumers likely would think twice before signing up with an insurer whose planning horizon is as short as one year. Given a longer-term perspective, insurers' strategies are influenced by two empirical facts, viz. decreasing precision of forecasts and regression to the (conditional) mean. The first fact causes the risk of misclassification to increase with a longer planning horizon. However, to the extent that the regression is to the conditional rather than the grand mean of $\mathrm{HCE}$, the second fact may serve to increase the payoffs to risk selection when the planning horizon is extended.

In this research, the effectiveness of risk adjustment schemes is assessed in the light of these considerations. Purely demographic risk adjustment already increases the likelihood of misclassification but does not sufficiently neutralize the longer-term, systematic differences in HCE to decisively mitigate the incentives for risk selection. For this, it takes a more refined formula that includes prior hospitalization and possibly Pharmaceutical Cost Groups (PCGs) as risk adjusters.

Gains from risk selection are estimated based on predicted HCE net of copayments, premiums, and risk adjustment payments, discounted to present value and weighted by the probabilities of death and of switching to a competitor to obtain expected values. These calculations are performed for four different risk adjustment schemes, viz. (0) no risk adjustment, (1) demographic risk adjustment, (2) demographic risk adjustment, with prior hospitalization added as a simple morbidity indicator, and (3) PCGs complementing scheme (2).

For a sample of some 180,000 Swiss individuals, expected net present values conditioned on the risk adjustment scheme were calculated. However, these values must exceed the variable cost associated with risk selection effort in order to trigger action on the part of the insurer. Since this cost is unknown, an arbitrary but not unrealistic value of $+/$ - CHF 1,000 p. a. ( $\$ 800$ as of 2007) serves as a threshold. Thus, the insurer is assumed to be indifferent with regard to risks whose contributions to expected profit fall within this interval.

The risk adjustment schemes distinguished modify incentives for risk selection according to expectations. The better they reflect morbidity, the smaller the share of the insured population that constitutes favorable and unfavorable risks, respectively. Adjustment using only age and sex (type 1) 
causes the share of favorable risks to drop from 56 to 40 percent, the share of unfavorable ones, from 21 to 18 percent. With schemes of type (2) and (3), the figures for the favorable risks drop to 26 and 20, and for the unfavorable risks, to 17 and 18 percent, respectively. It also should be noted that the characteristics of the subgroups change dramatically with type of risk adjustment. Average age of favorable customers increases from 46 (type 0 ) to 71 years (type 3 ), while the share of those belonging to one or more PCGs (in indicator of chronic illness) increases from 3 to 47 percent.

The success of risk selection efforts is reflected by the insurer's ability to lower premiums and hence gain market share. In the absence of risk adjustment, deterring all unprofitable risks is estimated to result in a 46 percent premium reduction over five years. This longer-term competitive advantage is reduced to 16 percent under type (3) risk adjustment, which takes into account both prior hospitalization and membership in a PCG. Interestingly, this figure is in the same range as the premium reductions that may be offered for participation in a managed care alternative, which constitutes a product innovation. Thus, it may be argued that type (3) risk adjustment is effective enough to redirect insurers' efforts from risk selection to product innovation.

In addition, the risk of misclassification is a mere 7 percent for an insurer "chasing the good risks" as long as there is no risk adjustment but increases to 25 percent under scheme (3). Refined risk adjustment therefore becomes even more effective than indicated by the expected contribution to profit because it exposes insurers to increased uncertainty.

In conclusion, this research suggests that risk adjustment can be designed in a way as to be effective enough in the longer term to redirect insurers' efforts away from risk selection in favor of product innovation while using easily available information such as prior hospitalization and membership in pharmaceutical cost groups. 


\section{References}

-van Barneveld E, Lamers L, van Vliet R, van de Ven W. Ignoring Small Predictable Profits and Losses: A New Approach for Measuring Incentives for Cream Skimming. Health Care Management Science 2000; Vol. 3; 131-140.

-Beck K. Risikoausgleich - Basis für einen sinnvollen Wettbewerb in der Krankenversicherung (Fondation of Efficiency-enhancing competition in Health Insurance). Mimeo. CSS Versicherung: Lucerne. 1998.

-Beck K, Zweifel P. Cream-Skimming in Deregulated Social Health Insurance: Evidence from Switzerland. In: Zweifel P (Ed.), Health, the Medical Profession, and Regulation. Kluwer: Dordrecht; 1998, 211-227.

-Beck K, Spycher S, Holly A, Gardiol L. Risk adjustment in Switzerland. Health Policy 2003; 65; 63-74.

-Beck K. Risiko Krankenversicherung - Risikomanagement in einem regulierten Krankenversicherungsmarkt (The Risky Business of Health Insurance. Risk Management in a Regulated Market for Health Insurance). Haupt: Bern; 2004.

-Beck K, Trottmann M, Käser U, Keller B, von Rotz S, Zweifel P. Nachhaltige Gestaltung des Risikoausgleichs in der Schweizer Krankenversicherung (Sustainable Design of Risk Adjustment in Swiss Health Insurance). h.e.p. Verlag: Bern; 2006.

-Duan N, Manning W, Morris C, Newhouse P. A Comparison of Alternative Models for the Demand for Medical Care. Journal of Business \& Economic Statistics 1983; Vol. 1; No. 2; 115 - 126.

-Ellis, R. Risk adjustment in health care markets: concepts and applications. In Lu, M, and Jonnson, E (Eds.). Financing Health Care: New Ideas for a Changing Society. Wiley-VCH Publishers Weinheim, Germany, 2008.

-Enthoven, A. Consumer-Choice Health Plan. The New England Journal of Medicine 1978; 298; No. 12; 650-658 and No. 13; 709-720.

-Holly A, Gardiol L, Eggli Y, Yalcin T. Health-based Risk Adjustment in Switzerland: an Exploration Using Medical Information from Prior Hospitalization. Mimeo; Institut d'économie et management de la santé: Lausanne; 2003.

-Lamers L, van Vliet R. Health-based Risk Adjustment: Improving the Pharmacy-based Cost Group Model to Reduce Gaming Possibilities. European Journal of Health Economics 2003; 4; 107-114.

-Manning W, Mullahy J. Estimating Log Models: To Transform Or Not To Transform? Journal of Health Economics 2001; 20; 461-494.

-Marchand M, Sato M, Schokkaert E. Prior Health Expenditures and Risk Sharing with Insurers Competing on Quality. Rand Journal of Economics 2004; 34; 647-669.

-Newhouse J. Is Competition the Answer? Journal of Health Economics 1982; 1; 109-116. 
-Newhouse J, Manning W, Keeler E, Sloss E. Adjusting Capitation Rates Using Objective Health Measures and Prior Utilization. Health Care Financing Review 1989; 10; No. 3; 41-54.

- Pauly M, Herring B. Pooling Health Insurance Risks. The AEI Press: Washington; 1999.

-Pauly M, Nickel A, Kunreuther H. Guaranteed Renewability with Group Insurance. Journal of Risk and Uncertainty 1998; 16; 211-221.

-Pope G, Ellis R, Ash A, Liu C, Ayanian J, Bates D, Burstin H, Iezzoni L, Ingber M. Principal Inpatient Diagnostic Cost Group Model for Medicare Risk Adjustment. Health Care Financing Review 2000; 21; No. 3; 93-118.

-Shen Y, Ellis R. How Profitable is Risk Selection? A Comparison of Four Risk Adjustment Models. Health Economics 2002; 11; 165-174.

-Van de Ven W, Ellis R. Risk Adjustment in Competitive Health Plan Markets. In: Newhouse J, Culyer A (Eds.), Handbook of Health Economics, vol. 1a. North-Holland: Amsterdam; 2000. p. 755-845.

-Van de Ven W, Beck K, Van de Voorde C, Wasem J, Zmora I. Risk Adjustment and Risk Selection in Europe: six years later. Mimeo; Erasmus University of Rotterdam: The Netherlands; 2006.

-Van Vliet, R.C.J.A. Predictability of Individual Health Care Expenditures. Journal of Risk and Insurance 1992; LIX (3); 443-460.

-Welch W. Regression Toward the Mean in Medical Care Costs - Implications for Biased Selection in HMOs. Medical Care 1985; 23; 1234-1241.

-Zweifel P, Felder S, Werblow A. Population Ageing and Health Care Expenditure: New Evidence on the Red Herring. The Geneva Papers on Risk and Insurance 2004; 29; 652-666.

-Zweifel P, Breuer M. The Case for Risk-Based Premiums in Public Health Insurance. Health Economics, Policy and Law 2006; 1; 171-188.

- Zweifel, P. The Theory of Social Health Insurance. Foundations and Trends in Microeconomics, 2007, 3, ( 3), 183-273. 
Table 1: Assumed risk selection strategies, $1 \mathrm{CHF} \approx 0.8 \$$

\begin{tabular}{|l|l|l|}
\hline Risk type & Characterization & Strategy \\
\hline A & $\begin{array}{l}\text { Expected profit } \\
>1000 \text { CHF p. a. }\end{array}$ & Attract \\
\hline B & $\begin{array}{l}\text { Expected profit } \\
\leq 1000 \text { CHF p. a. }\end{array}$ & Passive \\
\hline C & $\begin{array}{l}\text { Expected loss } \\
\leq 1000 \text { CHF p. a. }\end{array}$ & Passive \\
\hline D & $\begin{array}{l}\text { Expected loss } \\
>1000 \text { CHF p. a. }\end{array}$ & Deter \\
\hline
\end{tabular}

Table 2: Ranking of Pharmaceutical Cost Groups in terms of HCE

\begin{tabular}{|l|l|l|l|}
\hline Rank & PCG & $\begin{array}{l}\text { Population share, } \\
\text { in percent }\end{array}$ & $\begin{array}{l}\text { Average excess HCE, } \\
\text { in CHF per month }\end{array}$ \\
\hline 1 & Renal disease, ESRD & 0.06 & 3.484 \\
\hline 2 & HIV / AIDS & 0.11 & 1.529 \\
\hline 3 & Transplantations & 0.15 & 1.291 \\
\hline 4 & Malignancies & 0.13 & 970 \\
\hline 5 & Diabetes insulin-dep. & 0.75 & 558 \\
\hline 6 & Morbus Parkinson & 0.38 & 440 \\
\hline 7 & Epilepsy & 0.89 & 280 \\
\hline 8 & Respiratory illness \& Asthma & 2.16 & 248 \\
\hline 9 & Morbus Crohn, Colitis ulcerosa & 0.23 & 215 \\
\hline 10 & Diabetes non insulin-dep. & 2.40 & 180 \\
\hline 11 & Rheumatologic conditions & 2.85 & 165 \\
\hline 12 & Acid peptic disease & 0.59 & 142 \\
\hline 13 & Cardiac disease & 3.96 & 114 \\
\hline 0 & None & 85.33 & - \\
\hline $12 H F \approx 0.85$ & \\
\hline
\end{tabular}

$1 \mathrm{CHF} \approx 0.8 \$$ 
Table 3: The four risk adjustment formulas compared

\begin{tabular}{|l|l|}
\hline Formula No. & $\begin{array}{l}\mathbf{R}^{\mathbf{2}} \\
\text { Year: 2000 }\end{array}$ \\
\hline (0) None & 0.00 \\
\hline (1) Age, gender & 0.11 \\
\hline (2) Age, gender, prior hospitalization & 0.21 \\
\hline (3) Age, gender, prior hospitalization, PCG & 0.30 \\
\hline $\begin{array}{l}\text { Benchmark: } \\
\text { Insurer's own model }\end{array}$ & 0.48 \\
\hline
\end{tabular}

Table 4: Individual HCE net of deductible and coinsurance, 2000

\begin{tabular}{|l|l|l|l|l|}
\hline & female & male & constant & $-354 * * \circ$ \\
\hline $26-30$ & $492 * * \circ$ & reference cat. & HCE 97 & $0.109 * * \circ$ \\
\hline $31-35$ & $386 * * \circ$ & 28 & HCE 98 & $0.080^{* * \circ}$ \\
\hline $36-40$ & $229 *$ & 102 & physician services 99 & $0.540 * * \circ$ \\
\hline $41-45$ & $181 *$ & 122 & drugs doctors 99 & $0.947 * * \circ$ \\
\hline $46-50$ & $227 *$ & $229 *$ & drugs pharmacies 99 & $0.977 * * \circ$ \\
\hline $51-55$ & $321 * * \circ$ & $275 * *$ & inpatient care 99 & $0.347 * * \circ$ \\
\hline $56-60$ & $310 * * \circ$ & $424 * * \circ$ & home care 99 & $0.936^{* * \circ}$ \\
\hline $61-65$ & $472 * * \circ$ & $592 * * \circ$ & nursing home care 99 & $0.626 * * \circ$ \\
\hline $66-70$ & $643 * * \circ$ & $1042 * * \circ$ & other HCE 99 & $0.626 * * \circ$ \\
\hline $71-75$ & $1108 * * \circ$ & $1307 * * \circ$ & deductible 230 & $589 * * \circ$ \\
\hline $76-80$ & $1602 * * \circ$ & $1725 * * \circ$ & deductible 400 & $297 * * \circ$ \\
\hline $81-85$ & $2156 * * \circ$ & $2072 * * \circ$ & deductible 600 & 86 \\
\hline $86-90$ & $2886 * * \circ$ & $2666 * * \circ$ & deductible 1200 & 79 \\
\hline $91+$ & $2580 * * \circ$ & $2267 * * \circ$ & deductible 1500 & reference cat. \\
\hline
\end{tabular}

$\mathrm{R}^{2}=0.481, \mathrm{R}_{\mathrm{adj}}{ }^{2}=0.481, \mathrm{~F}=3750.2(\mathrm{df}=40) * *, \mathrm{n}=182^{\prime} 529$,

$* \mathrm{p} \leq 0.05, * * \mathrm{p} \leq 0.01,{ }^{\circ}$ Tchebycheff-significance level $10 \%$ 
Table 5: Effect of risk adjustment on the size of the four subgroups A-D

\begin{tabular}{|l|l|l|l|l|}
\hline \multicolumn{2}{|l|}{ Calculated shares in percent } & \multicolumn{2}{l|}{} \\
\hline Risk adjustment & A & B & C & D \\
\hline (0) None & 56 & 14 & 9 & 21 \\
\hline (1) Age, gender & 40 & 27 & 14 & 18 \\
\hline (2) Age, gender, prior hospitalization & 26 & 34 & 23 & 17 \\
\hline (3) Age, gender, prior hospitalization, PCG & 20 & 35 & 27 & 18 \\
\hline
\end{tabular}

With A : $\mathrm{E}\left[\pi_{\mathrm{i}, \mathrm{j}}\right]>1.000 ; \mathrm{B}: 0<\mathrm{E}\left[\pi_{\mathrm{i}, \mathrm{j}}\right]<1.000 ; \mathrm{C}: 0>\mathrm{E}\left[\pi_{\mathrm{i}, \mathrm{j}}\right]>-1.000 ; \mathrm{D}: \mathrm{E}\left[\pi_{\mathrm{i}, \mathrm{j}}\right]<-1.000$

Table 6: Effect of risk adjustment (RA) on composition of subgroups

\begin{tabular}{|c|c|c|c|c|c|c|c|c|c|c|c|c|}
\hline \multirow[t]{2}{*}{ Risk Adjustment } & \multicolumn{4}{|c|}{$\begin{array}{l}\text { Mean age in category, } \\
2000 \\
\text { Overall mean: } 54\end{array}$} & \multicolumn{4}{|c|}{$\begin{array}{l}\text { Mean net HCE per month, } \\
2000 \text { (CHF, prior to RA) } \\
\text { Overall mean: } 291\end{array}$} & \multicolumn{4}{|c|}{$\begin{array}{l}\text { Share of individuals in } \\
\geq 1 \mathrm{PCG}, 2000 \text { (percent) } \\
\text { Overall mean: } 15\end{array}$} \\
\hline & $\mathrm{A}$ & $\mathrm{B}$ & $\mathrm{C}$ & $\mathrm{D}$ & $\mathrm{A}$ & $\mathrm{B}$ & $\mathrm{C}$ & $\mathrm{D}$ & A & $\mathrm{B}$ & $\mathrm{C}$ & $\mathrm{D}$ \\
\hline (0) None & 46 & 59 & 64 & 67 & 77 & 211 & 320 & 910 & 3 & 16 & 27 & 40 \\
\hline (1) Age, gender & 62 & 44 & 44 & 56 & 175 & 130 & 197 & 856 & 11 & 8 & 14 & 33 \\
\hline (2) Age, gender, prior hospitalization & 70 & 49 & 45 & 51 & 328 & 138 & 176 & 713 & 20 & 8 & 11 & 26 \\
\hline $\begin{array}{l}\text { (3) Age, gender, prior hospitalization, } \\
\text { PCG }\end{array}$ & 71 & 51 & 46 & 51 & 441 & 132 & 159 & 631 & 47 & 7 & 4 & 10 \\
\hline
\end{tabular}


Table 7: Reduction of average premium thanks to deterring D-rated risks, in percent

\begin{tabular}{|l|l|}
\hline Risk adjustment & Possible premium reduction \\
\hline (0) None & 46 \\
\hline (1) Age, gender & 32 \\
\hline (2) Age, gender, prior hospitalization & 19 \\
\hline (3) Age, gender, prior hospitalization, PCG & 16 \\
\hline
\end{tabular}

Table 8: Financial advantage of attracting A-rated risks, in percent

\begin{tabular}{|l|l|l|l|l|}
\hline Risk adjustment & $\boldsymbol{x = 2}$ & $\boldsymbol{x}=\mathbf{4}$ & $\boldsymbol{x}=\mathbf{6}$ & $\boldsymbol{x}=\infty$ \\
\hline (0) None & 23 & 41 & 48 & 66 \\
\hline (1) Age, gender & 17 & 32 & 38 & 57 \\
\hline (2) Age, gender, prior hospitalization & 7 & 15 & 19 & 31 \\
\hline (3) Age, gender, prior hospitalization, PCG & 6 & 14 & 18 & 34 \\
\hline
\end{tabular}


Table 9: Frequency of misclassification

\begin{tabular}{|l|l|l|}
\hline Risk adjustment formula No. & $\begin{array}{l}\text { Percentage of A-rated custom- } \\
\text { ers who ex post turn out to } \\
\text { generate losses }\end{array}$ & $\begin{array}{l}\text { Percentage of D-rated cus- } \\
\text { tomers who ex post turn out } \\
\text { to generate gains }\end{array}$ \\
\hline (0) None & 7 & 24 \\
\hline (1) Age, gender & 15 & 28 \\
\hline (2) Age, gender, prior hospitalization & 23 & 35 \\
\hline (3) Age, gender, prior hospitalization, PCG & 25 & \\
\hline
\end{tabular}

Table 10: Size of subgroups $A$ and $D$ with different planning horizons

\begin{tabular}{|l|r|r|r|r|r|r|}
\hline \multirow{2}{*}{ Risk adjustment formula No. } & \multicolumn{3}{|l|}{ Percentage A-rated } & \multicolumn{3}{l|}{ Percentage D-rated } \\
\cline { 2 - 7 } & 1 year & 3 years & 5 years & 1 year & 3 years & 5 years \\
\hline (0) None & 70 & 68 & 56 & 18 & 18 & 21 \\
\hline (1) Age, gender & 52 & 49 & 40 & 19 & 19 & 18 \\
\hline (2) Age, gender, prior hospitalization & 44 & 39 & 26 & 18 & 18 & 17 \\
\hline (3) Age, gender, prior hospitalization, PCG & 40 & 34 & 20 & 18 & 18 & 18 \\
\hline
\end{tabular}


Table 11: Frequency of misclassification, different planning horizons

\begin{tabular}{|c|c|c|c|c|c|c|}
\hline \multirow[b]{2}{*}{ Risk adjustment formula No. } & \multicolumn{3}{|c|}{$\begin{array}{l}\text { Percentage of A-rated customers } \\
\text { who ex post turn out to generate } \\
\text { losses }\end{array}$} & \multicolumn{3}{|c|}{$\begin{array}{l}\text { Percentage of D-rated customers } \\
\text { who ex post turn out to generate } \\
\text { gains }\end{array}$} \\
\hline & 1 year & 3 years & 5 years & 1 year & 3 years & 5 years \\
\hline (0) None & 10 & 11 & 7 & 33 & 31 & 24 \\
\hline (1) Age, gender & 10 & 15 & 15 & 33 & 31 & 28 \\
\hline (2) Age, gender, prior hospitalization & 13 & 21 & 23 & 43 & 40 & 35 \\
\hline (3) Age, gender, prior hospitalization, PCG & 15 & 21 & 25 & 45 & 41 & 38 \\
\hline
\end{tabular}

Table 12: Premium reductions thanks to risk selection, different planning horizons (percent of average premium)

\begin{tabular}{|c|c|c|c|c|c|c|}
\hline & \multicolumn{3}{|c|}{ Gains from attracting $\mathrm{A}, \mathrm{x}=4$} & \multicolumn{3}{|c|}{ Gains from deterring D } \\
\hline Risk adjustment formula No. & 1 year & 3 years & 5 years & 1 year & 3 years & 5 years \\
\hline (0) None & 37 & 35 & 41 & 45 & 40 & 46 \\
\hline (1) Age, gender & 35 & 31 & 32 & 38 & 33 & 32 \\
\hline (2) Age, gender, prior hospitalization & 18 & 17 & 15 & 19 & 19 & 19 \\
\hline (3) Age, gender, prior hospitalization, PCG & 18 & 17 & 14 & 17 & 17 & 16 \\
\hline
\end{tabular}


Figure 1: Expected individual profits without risk adjustment (0)

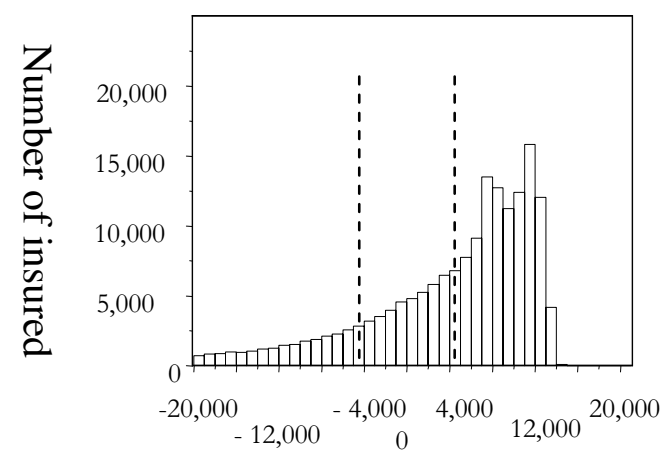

Mean: 0, Std. deviation: 20,018

1. - 3. quartile: $-2,095$ / 5,985 / 9,900

Interquartile range: 11,995

$\mathrm{E}\left[\pi_{\mathrm{i}, \mathrm{j}}\right]<-20,000: 15,029$ individuals

Expected individual profits, $\mathrm{E}\left[\pi_{\mathrm{i}, \mathrm{j}}\right]$

Figure 2: Expected individual profits with risk adjustment (3)

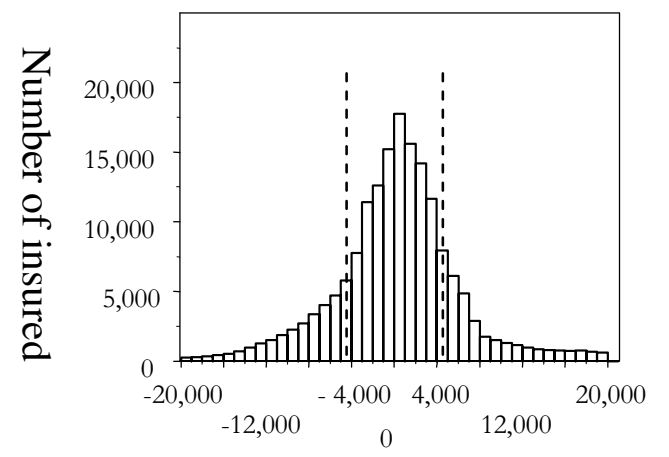

Mean: 0, Std. deviation: 14,536

1. - 3. quartile: $-2,798$ / 489 / 3,543

Interquartile range: 6,341

$\mathrm{E}\left[\pi_{\mathrm{i}, \mathrm{j}}\right]<-20,000: 4,767$ individuals

$\mathrm{E}\left[\pi_{\mathrm{i}, \mathrm{j}}\right]>20,000:$ 7,019 individuals

Expected individual profits, $\mathrm{E}\left[\pi_{\mathrm{i}, \mathrm{j}}\right]$ 